\title{
Increased risk of non-AIDS-defining cancers in Asian HIV-infected patients: a long-term cohort study
}

\author{
Naoyoshi Nagata ${ }^{1 *}$, Takeshi Nishijima ${ }^{2}$, Ryota Niikura ${ }^{3}$, Tetsuji Yokoyama ${ }^{4}$, Yumi Matsushita ${ }^{5}$, Koji Watanabe ${ }^{2}$, \\ Katsuji Teruya ${ }^{2}$, Yoshimi Kikuchi ${ }^{2}$, Junichi Akiyama', Mikio Yanase', Naomi Uemura ${ }^{6}$, Shinichi Oka ${ }^{2}$ \\ and Hiroyuki Gatanaga ${ }^{2}$
}

\begin{abstract}
Background: Data on the long-term risks of non-AIDS defining cancers (NADCS) are limited, especially in Asians. The incidence of NADCs may correlate with the epidemiological trend of cancers or oncogenic infection in each country, and thus the target cancers would be different between Western and Asian countries. We aimed to elucidate the incidence of NADCs and its predictive factors in Asian HIV-infected patients.

Methods: Subjects were HIV-infected patients $(n=1001)$ periodically followed-up for 9 years on average. NADCs were diagnosed by histopathology and/ or imaging findings. Standardized incidence ratios (SIR) were calculated as the ratio of the observed to expected number of NADCs for comparison with an age-and sex-matched general population. Cox's proportional hazards model was used to estimate hazard ratios (HR).

Results: During the median follow-up of 9 years, the 10-year cumulative incidence of NADCs was 6.4\%.At NADC diagnosis, half of patients presented at age 40-59 years and with advanced tumor stage. Compared with the age-and sex-matched general population, HIV-infected patients are at increased risk for liver cancer $(S I R, 4.7)$, colon cancer $(S I R, 2.1)$, and stomach cancer $(S I R, 1.8)$. In multivariate analysis, a predictive model for NADCs was developed that included age group (40-49, 50-59,60-69, and $\geq 70$ years), smoker, HIV infection through blood transmission, and injection drug use (IDU), and HBV co-infection. The c-statistic for the NADCs predictive model was $0.8(95 \% \mathrm{Cl}, 0.8-0.9, P<0.001)$. The higher 10-year incidence rate of NADCs was associated with increasing prediction score.
\end{abstract}

Conclusions: Liver and colon cancer risk was elevated in Asian HIV-infected individuals, similar to in Western populations, whereas stomach cancer risk was characteristically elevated in Asian populations. Half of Asian NADC patients were aged 40-59 years and had advanced-stage disease at diagnosis. Periodic cancer screening may be warranted for high-risk subpopulations with smoking habit, HIV infection through blood transmission or IDU, and HBV co-infection, and screening should be started over 40 years of age.

Keywords: Non-AIDS-defining malignancies, Gastric cancer, Colorectal cancer, Liver cancer, Lung cancer, All-cause mortality, Hepatitis viral infection, Highly active antiretroviral therapy

\footnotetext{
* Correspondence: nnagata_ncgm@yahoo.co.jp

${ }^{1}$ Departments of Gastroenterology and Hepatology, National Center for

Global Health and Medicine, 1-21-1 Toyama, Shinjuku-ku, Tokyo 162-8655,

Japan

Full list of author information is available at the end of the article
}

(c) The Author(s). 2018 Open Access This article is distributed under the terms of the Creative Commons Attribution 4.0 International License (http://creativecommons.org/licenses/by/4.0/), which permits unrestricted use, distribution, and reproduction in any medium, provided you give appropriate credit to the original author(s) and the source, provide a link to the Creative Commons license, and indicate if changes were made. The Creative Commons Public Domain Dedication waiver (http://creativecommons.org/publicdomain/zero/1.0/) applies to the data made available in this article, unless otherwise stated. 


\section{Background}

The incidence of non-AIDS-defining cancers (NADCs) has been increasing and is a significant source of morbidity and mortality in the HIV-infected population [1-7]. Most data on NADC risk are available for Western countries [1-3, 6, 7] and little data from Asia are available $[4,5]$. Compared with the general population, people infected with HIV have an increased risk of some NADCs [1-7], and NADCs are now being diagnosed at a much younger age $[8,9]$. However, there are no definitive guidelines for NADC screening, and most organization guidelines for cancer screening do not make recommendations that are different for HIV-infected patients. As it stands, most clinicians caring for HIV patients may perform only age-appropriate cancer screening [10].

NADC screening should be effective and low cost, and it is therefore recommended for people who are at high risk for cancer. However, few studies have investigated the detailed risk factors for NADCs. In addition, it is not yet known which cancers should be noted in screening in the long-term management of HIV-infected patients. It is possible that the incidence of NADCs may correlate with the epidemiological trend of cancers or oncogenic infection in each country, and thus the target cancers would be different between Western and Asian countries.

In consideration of these issues, we aimed to elucidate i) the incidence of NADCs during the long-term follow-up of HIV patients, ii) the standardized incidence ratio (SIR) of each NADC in comparison with the general Japanese population, and iii) predictive factors for NADC development.

\section{Methods}

\section{Study design, setting, and participants}

We conducted a retrospective cohort study using data from a prospectively recorded electronic database (MegaOak online imaging system, NEC, Japan, and SolemioEndo, Olympus, Japan) between January 1997 through December 2015. This database is a searchable collection of records into which physicians and nurses immediately input all clinical findings after patient examinations. We included 1185 Japanese adult patients with HIV type 1 (HIV-1) infection who were diagnosed at the AIDS Clinical Center and/or Department of Gastroenterology and Hepatology, or were referred from other medical institutions to the AIDS Clinical Center at the National Center for Global Health and Medicine, Tokyo, Japan. More than $95 \%$ of patients initially visited the AIDS Clinical Center. All HIV-infected patients were followed-up at the AIDS Clinical Center and were managed by HIV infection experts. Our hospital has one of the largest HIV clinics, treating approximately $15 \%$ of HIV-infected patients in Japan [11]. First, we reviewed all radiologic, endoscopic, surgical, pathological, and other clinical data in the electronic medical record system for these 1185 patients. We excluded the following patients: i) those referred from other hospitals for treatment or investigation for cancer and those who had cancer before or at the time of diagnosis of HIV infection at our institution $(n=28)$; (ii) those whose clinical information could not be sufficiently collected $(n=31)$; iii) those who visited our hospital only once $(n=176)$; and iv) those whose HIV infection was diagnosed 0-3 months prior to review $(n=41)$ because the cancer risk in this period can appear artificially high due to intensive medical evaluations. More than one exclusion criterion applied to some patients. Finally, a cohort of 1001 HIV-infected patients who were periodically followed up was selected for analysis. Because this was a retrospective cohort study that was conducted without invasive procedures, and patient information was anonymized and deidentified before analysis, the requirement for patient consent was waived. This study was approved by the ethics committee of the National Center for Global Health and Medicine (Nos.1424 and 1440) and was implemented in accordance with the provisions of the Declaration of Helsinki.

\section{Data collection and follow-up}

In accordance with our specific institutional protocol, all patients when first seen at our hospital were systematically screened for hepatitis B virus (HBV) and hepatitis $C$ virus $(\mathrm{HCV})$ infection and their $\mathrm{CD} 4$ cell count and HIV-1 viral load were determined [12]. A positive result for the hepatitis B surface antigen indicated HBV infection. In Japan, because universal vaccination against HBV has not been introduced and intervention to prevent mother-to-child transmission has been highly successful [13], most adult cases with chronic HBV infection are considered to be sexually transmitted [14]. $\mathrm{HCV}$ infection was defined as the presence of HCV antibodies. Since 1997, patients on their first visit to the AIDS clinical center have completed a detailed, structured questionnaire during a face-to-face interview with well-trained researchers in a private room. Patients were asked about their lifestyle habits (smoking history and alcohol consumption), medications, past history and co-morbidities, and presumed route of transmission for HIV infection (men who have sex with men [MSM], heterosexual, blood transmission, or injection drug use [IDU]). During the follow-up period, most patients visited our hospital every 1-3 months. The prescription period for all drugs under the health care system is limited to 3 months in Japan, so patients need to make visits at least once during this period for prescriptions as well as for monitoring of CD4 cell count, HIV viral load, or serological tests. In Japan where there is a high 
incidence of gastric, colorectal, liver, and lung cancers, endoscopy and computed tomography (CT) are frequently performed for cancer screening, even as part of routine examinations for patients without symptoms of the disease.

\section{Diagnosis of non-AIDS-defining cancers}

The diagnosis of NADCs was based on histopathological or cytological examination of the resected specimen, biopsy, tumor brush, or fluid samples obtained percutaneously, during upper or lower endoscopy, bronchoscopy, or surgery. When a cancer was suspected or confirmed, MDCT with other imaging modalities was performed in all patients. Gastrointestinal cancer included cancers affecting the oral cavity, esophagus, stomach, colon, and anorectum. Staging of NADCs was based on the TNM classification, and tumors were staged according to the Union for International Cancer Control (UICC) classification [15].

\section{Statistical analysis}

To estimate the actual incidence of the respective NADCs, we analyzed those patients who did not have NADC before and at the time of diagnosis of HIV infection at our institution (index date). We followed up patients from the diagnosis of HIV infection at our institution (index date) to the diagnosis of any NADC as the primary endpoint. Data were censored at the time of the last visit, or death, or at the end of the follow-up period (December 31, 2015). The diagnosis of NADCs was defined as occurrence of first primary cancer, and multiple cancer per patient was not assessed in this study. The Kaplan-Meier method was used to estimate the cumulative incidence of any NADC at 1, 5, 10, and 15 years.

In the comparison with the general population, we evaluated the expected cancer rate based on vital statistics data for Japan. The expected number of NADCs was determined using age-stratified and sex-specific data on the incidence of cancer in Japan, provided by the Center for Cancer Control and Information Services, National Cancer Center, Japan [16]. Because cancer rates are provided for 5-year age groups in Japan, 5-year age groups were used for the calculation of age-specific rates, for the cumulative rate 20-84 years of age. The standardized incidence ratio (SIR) was calculated as the ratio of the observed number to the expected number of patients developing NADCs. The $95 \%$ confidence interval (CI) of the SIR was estimated, assuming a Poisson distribution following a variance-stabilizing transformation. Statistical analysis of SIR was performed using SAS software version 9.4 (SAS Institute, Cary, NC, USA).

Predictive factors were assessed at enrollment, and time-fixed covariates were included in the time-to-event models. Predictive factors for NADCs were examined using Cox's proportional hazards models. We estimated unadjusted and adjusted hazard ratios (HRs) and 95\% confidence intervals (CIs). In multivariate analysis, we adjusted for factors including age category, smoker, HIV risk category, $\mathrm{HBV}$ infection, $\mathrm{HCV}$ infection, diabetes mellitus with end-organ damage, congestive heart failure, and chronic moderate to severe liver disease that showed an association with NADC $(p<0.2)$ in univariate analysis. A final model was then developed by backward selection of factors showing values of $p<0.1$. The weight of each predictor was determined according to the coefficients in the model. Based on the final model's regression coefficients, points were assigned as follows: 1 point each for blood transmission and HBV infection; 2 points each for age 40-49, smoker, and injection drug use; 3 points each for age 50-59 and age 60-69; and 4 points for age $\geq 70$. The accuracy of the predictive model for NADCs was evaluated by the c-statistics using Harrell's method. [17] Values of $p<0.05$ were considered significant. All statistical analyses were performed using STATA version 13 software (StataCorp, College Station, TX).

\section{Results}

\section{Baseline characteristics}

Patient characteristics are shown in Table 1. Various HIV risk groups were identified: the majority of patients were MSM at $75.2 \%$, followed by heterosexuals at $12.3 \%$, hemophilia at $9.5 \%$, IDU at $0.8 \%$, and transfusion at $0.5 \%$. At enrollment, median CD4 was 100 cells $/ \mu \mathrm{L}$ and median HIV-VL was 63,000 copies/mL. The proportion of patients receiving antiretroviral therapy at enrollment was $31.2 \%$. The positive rates of $\mathrm{HBV}, \mathrm{HCV}$, and both HBV and HCV infection in our cohort were 15.1\%, $14.5 \%$, and $1.5 \%$, respectively. Among the comorbidities, the most common were chronic liver disease (14.1\%), dyslipidemia (12.9\%), hypertension (10.2\%), diabetes mellitus (8.0\%), and chronic kidney disease (6.4\%) in this order.

\section{Development of NADCs and comparison with the general population}

During a median follow-up of 9.0 years, 61 NADCs (6.1\%) developed in 1001 HIV patients (Table 2). The overall incidence of NADCs was 9.19 per 1000 personyears. Total follow-up time was 8756.7 person-years. The cumulative probability of NADCs at $1,5,10$, and 15 years was $1.3 \%, 3.7 \%, 6.4 \%$, and $8.8 \%$, respectively (Fig. 1). The characteristics of patients at the time of NADC diagnosis are shown in Table 2. Half of patients (49.2\%) had an advanced tumor stage (III or IV) according to the Union for International Cancer Control classification. Median age was 57 years. The majority of HIV 
Table 1 Patients characteristics ( $N=1001)$

\begin{tabular}{|c|c|}
\hline Median age (IQR), years & $38(31-48)$ \\
\hline 20-39 & $551(55.0 \%)$ \\
\hline $40-49$ & $239(23.9 \%)$ \\
\hline $50-59$ & $139(13.9 \%)$ \\
\hline $60-69$ & $56(5.6 \%)$ \\
\hline$\geq 70$ & $17(1.7 \%)$ \\
\hline Sex (male) & $942(94.1 \%)$ \\
\hline Alcohol drinker & $557(55.6 \%)$ \\
\hline Smoker & $421(42.1 \%)$ \\
\hline \multicolumn{2}{|l|}{ Year of entry } \\
\hline 1997-2001 & $267(26.7)$ \\
\hline $2002-2006$ & $331(33.1)$ \\
\hline 2007-2011 & $309(30.9)$ \\
\hline $2012-2015$ & $94(9.4)$ \\
\hline \multicolumn{2}{|l|}{ HIV-related factors } \\
\hline \multicolumn{2}{|l|}{ HIV risk group } \\
\hline MSM & $753(75.2 \%)$ \\
\hline Heterosexuals & $123(12.3 \%)$ \\
\hline Blood transmission ${ }^{a}$ & $99(9.9 \%)$ \\
\hline Injection drug use & $8(0.8 \%)$ \\
\hline Unknown & $18(1.8 \%)$ \\
\hline Median CD4 (IQR), cells/ $\mu \mathrm{L}$ & 100 (30-184) \\
\hline CD4 <200, cells/ $\mu \mathrm{L}$ & 777 (77.6) \\
\hline $200-499$ & $209(20.9)$ \\
\hline$\geq 500$ & $15(1.5)$ \\
\hline Median HIV VL (IQR), copies/mL & $\begin{array}{l}63,000(5400-310,000) \\
(4.4-5.6)\end{array}$ \\
\hline HIV VL < 400, copies/mL & $166(16.6)$ \\
\hline $400-75,000$ & $360(36.0)$ \\
\hline$>75,000$ & $475(47.5)$ \\
\hline On antiretroviral therapy & $312(31.2)$ \\
\hline HBV infection alone & $151(15.1 \%)$ \\
\hline HCV infection & 145 (14.5\%) \\
\hline HBV and HCV co-infection & $15(1.5 \%)$ \\
\hline \multicolumn{2}{|l|}{ Co-morbidities } \\
\hline Hypertension & $102(10.2 \%)$ \\
\hline Dyslipidemia & $129(12.9 \%)$ \\
\hline Diabetes mellitus (uncomplicated) & $80(8.0 \%)$ \\
\hline Diabetes mellitus (end-organ damage) & $32(3.2 \%)$ \\
\hline Myocardial infarction & $9(0.9 \%)$ \\
\hline Congestive heart failure & $15(1.5 \%)$ \\
\hline Peripheral vascular disease & $2(0.2 \%)$ \\
\hline Cerebrovascular disease & $16(1.6 \%)$ \\
\hline Dementia & $14(1.4 \%)$ \\
\hline COPD & $7(0.7 \%)$ \\
\hline
\end{tabular}

Table 1 Patients characteristics $(N=1001)$ (Continued)

\begin{tabular}{|c|c|}
\hline Connective tissue disease & $2(0.2 \%)$ \\
\hline Peptic ulcer disease & $31(3.1 \%)$ \\
\hline Chronic kidney disease & $64(6.4 \%)$ \\
\hline Hemiplegia & $1(0.1)$ \\
\hline Chronic liver disease & $141(14.1 \%)$ \\
\hline Mild & $105(10.5 \%)$ \\
\hline Moderate to severe & $36(3.6 \%)$ \\
\hline
\end{tabular}

patients diagnosed with NADCs were in the age group $40-59$ years at $50.8 \%$, followed by the patients in the age group $60-79$ years at $37.7 \%$. All patients received antiretroviral therapy at the time of NADC diagnosis.

The observed number and SIR of each NADC are listed in Table 3. Half of NADCs were gastrointestinal cancer. Among NADCs, the incidence of liver cancer, colon cancer, and gastric cancer was significantly increased in HIV patients relative to the general population. Their SIR was as follows: liver cancer, 4.7; colon cancer, 2.1; and gastric cancer, 1.8.

\section{Predictive factors for NADCs}

The predictive factors for NADCs are shown in Table 4. In the univariate analysis, factors associated with NADC $(p<0.2)$ were advanced age, smoker, heterosexuality,

Table 2 Development of non-AIDS-defining cancers (NADCs) in patients with HIV infection ( $N=1001)$

\begin{tabular}{|c|c|}
\hline Development of NADCs & $61(6.1 \%)$ \\
\hline Development of gastrointestinal NADCs & $31(3.1 \%)$ \\
\hline Median follow-up period (IQR), years & $9.0(4.8-13.2)$ \\
\hline \multicolumn{2}{|l|}{ Stage at the time of NADC diagnosis ${ }^{\mathrm{a}}$} \\
\hline 0 or 1 & $14(22.9 \%)$ \\
\hline$\|$ & $17(27.9 \%)$ \\
\hline III & $9(14.8 \%)$ \\
\hline IV & $21(34.4 \%)$ \\
\hline \multicolumn{2}{|l|}{ Age at the time of NADC diagnosis, years } \\
\hline Median age (IQR) & $57(49-65)$ \\
\hline $20-39$ & $5(8.2 \%)$ \\
\hline $40-59$ & $31(50.8 \%)$ \\
\hline $60-79$ & $23(37.7 \%)$ \\
\hline $80-89$ & $2(3.3 \%)$ \\
\hline Antiretroviral therapy at the time of NADC diagnosis ${ }^{a}$ & $61(100 \%)$ \\
\hline
\end{tabular}




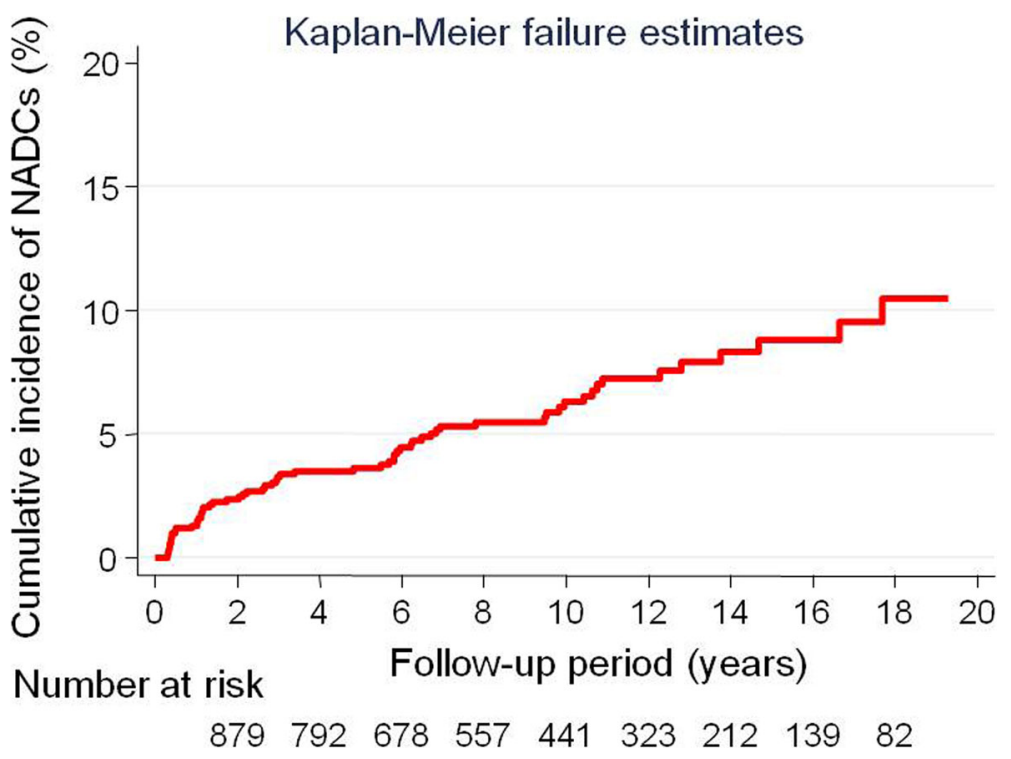

Fig. 1 The cumulative incidence of developing NADCs. The cumulative probability of NADCs (95\% confidence interval) at 1, 5, 10, and 15 years was $1.3 \%(0.77-2.3), 3.7 \%(2.6-5.1), 6.4 \%(4.8-8.3)$, and $8.8 \%(6.7-11.6)$, respectively

IDU, HBV infection, $\mathrm{HCV}$ infection, diabetes mellitus (end-organ damage), congestive heart failure, and moderate to severe chronic liver disease. In multivariate analysis, a final prediction model for NADCs was developed that included age at 40-49, age at 50-59, age at 60-69, age $\geq 70$, smoker, blood transmission, IDU, and HBV

Table 3 Observed and expected number of non-AIDS-defining cancers (NADCs) and all-cause deaths in patients with HIV compared with the general population in Japan

\begin{tabular}{llll}
\hline Cancer type & Observed & Expected & SIR $(95 \% \mathrm{Cl})$ \\
\hline Liver & 9 & 1.9 & $4.7(2.1-8.2)$ \\
Colorectal & 15 & 7.7 & $1.9(1.1-3.0)$ \\
Colon & 10 & 4.7 & $2.1(1.0-3.7)$ \\
Anorectal* & 5 & 3.1 & $1.6(0.5-3.4)$ \\
Gastric & 11 & 6.0 & $1.8(1.0-3.1)$ \\
Lung & 8 & 4.4 & $1.8(0.8-3.3)$ \\
Oral cavity and pharynx & 3 & 1.0 & $2.9(0.5-7.0)$ \\
Esophageal & 2 & 1.4 & $1.4(0.1-4.0)$ \\
Pancreas & 1 & 1.2 & $0.8(<0.1-3.3)$ \\
Biliary tract & 2 & 0.6 & $3.2(0.3-9.2)$ \\
Bladder & 2 & 0.8 & $2.4(0.2-6.7)$ \\
Skin & 1 & 0.6 & $1.8(<0.1-6.9)$ \\
Prostate & 1 & 4.0 & $0.2(<0.1-1.0)$ \\
Thyroid & 1 & 0.6 & $1.7(<0.1-6.5)$ \\
Breast & 1 & 0.8 & $1.3(<0.1-5.0)$ \\
Hodgkin lymphoma & 4 & $\mathrm{NA}^{\mathrm{a}}$ & $\mathrm{NA}$ \\
\hline Note & &
\end{tabular}

Note. ${ }^{*}$ Anorectal cancer included rectal cancer $(n=2)$ and anal cancer $(n=3)$. ${ }^{a}$ General population data were not available for Hodgkin lymphoma Abbreviation Standardized incidence ratio, SIR standardized mortality ratio infection (Table 4). A predictive model for NADCs was developed using eight factors. Based on the final model's regression coefficients (Table 4), points were assigned as follows: 1 point each for blood transmission and HBV infection; 2 points each for age 40-49, smoker, and injection drug use; 3 points each for age 50-59 and age 60-69; and 4 points for age $\geq 70$. The c-statistic for the NADC predictive model was $0.8(95 \% \mathrm{CI}, 0.8-0.9, P<$ 0.001 ) (Table 5). The higher 5 - and 10-year incidence rates of NADCs were associated with increasing prediction score. The HRs for NADCs were also associated with increasing prediction score $(p<0.001$ for trend).

\section{Discussion}

This long-term follow-up study focused on the development of NADCs and its predictive factors among 1001 HIV patients. Several important findings were noted. First, during the median follow-up of 9 years, the 10-year cumulative incidence of NADCs was $6.4 \%$. Second, half of NADC patients were aged 40-59 years and had advanced-stage disease at diagnosis. Third, compared with the age-and sex-matched general population, HIV patients were at increased risk of liver, colon, and stomach cancers. Fourth, a predictive model for NADCs was developed that included age group (40-49, $50-59,60-69$, and $\geq 70$ years), smoker, HIV infection through blood transmission, and injection drug use (IDU), and HBV co-infection.

To our knowledge, this is the first study to show a higher incidence of stomach cancer in HIV patients than in the general population. One study showed an elevated risk of stomach cancer in HIV patients compared with 
Table 4 Risk factors for non-AIDS-defining cancers (NADCs) in HIV-infected patients $(N=1001)$

\begin{tabular}{|c|c|c|c|c|c|}
\hline Factors & Crude HR (95\% CI) & $P$ value & Adjusted HR $(95 \% \mathrm{Cl})$ & Coefficient $^{\mathrm{a}}(95 \% \mathrm{Cl})$ & $P$ value \\
\hline Age $<40$ (years) & 1 (reference) & & 1 (reference) & & \\
\hline $40-49$ & $5.1(2.2-11.6)$ & $<0.001$ & $5.4(2.4-12.3)$ & $1.7(0.9-2.5)$ & $<0.001$ \\
\hline $50-59$ & $12.7(5.8-27.7)$ & $<0.001$ & $15.3(6.7-34.6)$ & $2.7(1.9-3.5)$ & $<0.001$ \\
\hline $60-69$ & $13.0(5.0-34.1)$ & $<0.001$ & $17.1(6.4-46.2)$ & $2.8(1.9-3.8)$ & $<0.001$ \\
\hline$\geq 70$ & $36.4(12.8-103.7)$ & $<0.001$ & $47.3(16.2-138.1)$ & $3.9(2.8-4.9)$ & $<0.001$ \\
\hline Sex (male) & $1.3(0.4-4.2)$ & 0.653 & & & \\
\hline Alcohol drinker & $1.0(0.6-1.7)$ & 0.876 & & & \\
\hline Smoker & $4.5(2.5-8.1)$ & $<0.001$ & $5.4(3.0-9.8)$ & $1.7(1.1-2.3)$ & $<0.001$ \\
\hline HIV risk group, MSM or unknown & 1 (reference) & & 1 (reference) & 1 (reference) & \\
\hline Heterosexuals & $1.9(1.0-3.7)$ & 0.045 & $1.6(0.8-3.2)$ & $0.5(-0.2-1.2)$ & 0.142 \\
\hline Blood transmission & $1.1(0.5-2.4)$ & 0.765 & $2.6(1.2-5.8)$ & $1.0(0.1-1.8)$ & 0.021 \\
\hline Injection drug use & $9.1(2.2-37.7)$ & 0.002 & $5.4(1.2-23.3)$ & $1.7(0.2-3.2)$ & 0.025 \\
\hline 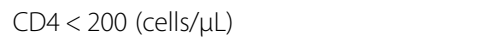 & $0.7(0.4-1.2)$ & 0.222 & & & \\
\hline HIV VL > 75,000 ( $\log _{10}$ copies/mL) & $1.00(0.6-1.6)$ & 0.972 & & & \\
\hline HBV infection & $1.8(1.0-3.3)$ & 0.059 & $1.8(1.0-3.5)$ & $0.6(-0.03-1.2)$ & 0.060 \\
\hline HCV infection & $1.6(0.9-2.9)$ & 0.120 & & & \\
\hline Hypertension & $1.2(0.6-2.5)$ & 0.619 & & & \\
\hline Dyslipidemia & $0.8(0.3-1.7)$ & 0.494 & & & \\
\hline Diabetes mellitus (uncomplicated) & $1.5(0.7-3.2)$ & 0.337 & & & \\
\hline Diabetes mellitus (end-organ damage) & $2.3(0.8-6.3)$ & 0.111 & & & \\
\hline Myocardial infarction & $1.8(0.2-12.8)$ & 0.569 & & & \\
\hline Congestive heart failure & $2.6(0.6-10.7)$ & 0.182 & & & \\
\hline Peripheral vascular disease & $N A^{*}$ & $N A^{*}$ & & & \\
\hline Cerebrovascular disease & $1.9(0.5-7.8)$ & 0.373 & & & \\
\hline Dementia & $1.2(0.2-8.7)$ & 0.857 & & & \\
\hline COPD & $N A^{*}$ & $N A^{*}$ & & & \\
\hline Connective tissue disease & $N A^{*}$ & $N A^{*}$ & & & \\
\hline Peptic ulcer disease & $1.1(0.3-4.4)$ & 0.921 & & & \\
\hline Chronic kidney disease & $0.5(0.2-2.1)$ & 0.352 & & & \\
\hline Hemiplegia & NA & $N A^{*}$ & & & \\
\hline Chronic liver disease (mild) & $1.2(0.6-2.5)$ & 0.680 & & & \\
\hline Chronic liver disease (moderate to severe) & $2.6(1.1-6.6)$ & 0.037 & & & \\
\hline
\end{tabular}

Note. *Statistical analysis could not be performed because there were no cases with the factor among patients with NADCs or those who died. ${ }^{a}$ Multiple Cox's proportional hazard modeling was used with backward elimination for factors that were found to be significant $(p<0.2)$ on univariate analysis. Abbreviations: $C I$ confidence interval, HBV hepatitis B virus, HCV hepatitis $C$ virus, MSM men who have sex with men, VL viral load, COPD chronic obstructive pulmonary disease, NADCs non-AIDS-defining cancers

the general population, but the report has subsequently been retracted and the corrected SIR is no longer significantly elevated [18]. The high incidence of stomach cancer in Japan compared with Western countries is due to the higher prevalence of Helicobacter pylori infection [19], or the higher occurrence in Japan of the precancerous condition of intestinal metaplasia due to $H$. pylori infection compared with Western and other Asian countries [20, 21]. We suggest that decreased immunity in HIV patients may result in increased exposure to infection and severe gastritis, leading to increased risk of stomach cancer, because immune function is necessary to sustain $H$. pylori infection and the accompanying inflammation [22]. Although few studies have investigated the incidence of NADCs in Asia [4, 5], our result of a high incidence of liver and colon cancers in HIV patients compared with the general population is consistent with the results of reports from Western countries [1, 3, 6, 7]. The repartition of observed NADCs might be correlated with the cancers found commonly in each country. 
Table 5 Scoring model for the prediction of non-AIDS-defining cancers (NADCs) in HIV-infected patients $(N=1001)$

\begin{tabular}{lllll}
\hline Score & No. of NADCs/ Non-NADCs & $\begin{array}{l}\text { Cumulative incidence rate } \\
\text { of NADCs at } 5 \text { years }(95 \% \mathrm{Cl})\end{array}$ & $\begin{array}{l}\text { Cumulative incidence rate of } \\
\text { NADCs at } 10 \text { years }(95 \% \mathrm{Cl})\end{array}$ & Hazard ratio (95\% Cl) \\
\hline 0 & $2 / 222$ & $0.9(0.2-3.7)$ & $0.9(0.2-3.7)$ & 1 (reference) \\
1 & $1 / 91$ & 0 & $1.4(0.2-9.7)$ & $0.9(0.08-10.2)$ \\
2 & $6 / 273$ & $0.4(0.1-2.8)$ & $1.4(0.4-4.4)$ & $2.5(0.5-12.3)$ \\
3 & $8 / 174$ & $2.9(1.2-6.9)$ & $2.9(1.2-6.9)$ & $5.1(1.1-23.9)$ \\
4 & $11 / 101$ & $5.8(2.7-12.5)$ & $10.7(5.5-20.4)$ & $12.6(2.8-56.7)$ \\
$\geq 5$ & $33 / 79$ & $20.2(13.5-29.7)$ & $41.3(29.7-55.3)$ & $53.2(12.7-222.5)$ \\
Total & $61 / 940$ & & & $P$ for trend $<0.001$ \\
\hline
\end{tabular}

C-statistics: $0.8(95 \% \mathrm{Cl}, 0.8-0.9, P<0.001)$

Note. Based on the final model's regression coefficients (Table 4), 1 point each was assigned to blood transmission, and HBV, 2 points each were assigned to age 40-49, smoker, and IDU, 3 points was assigned to age 50-59, age 60-69, and 4 points was assigned to age $\geq 70$. Abbreviations: $C l$ confidence interval, $H B V$ hepatitis $B$ virus, IDU injection drug use, NADCs non-AIDS-defining cancers

Indeed, the prevalent pattern of cancers in HIV patients in our study reflects the cancer incidence in Japan [16].

Our prediction scoring system could answer the question about which HIV patients should be screened for NADCs. In this study, the higher age groups of 40-49, $50-59,60-69$, and $\geq 70$ with reference to age $<40$ were associated with a greater hazard ratio for NADCs, in agreement with past reports $[1,23]$. In addition, more than half of NADCs were diagnosed in the 40-59 age group. Because many people living with HIV can expect to live as long as those without HIV [24], the factor of age seems to be one of the most important to consider in cancer screening, and HIV patients should start receiving screening over 40 years of age.

In agreement with past reports [7, 25], smoking was an independent risk factor in our study. Smoking is more common among HIV patients, at 57\%, than in those without, at 33\% [25]. Smoking is also known to suppress the immune system [26] and increase cancer risk. A literature review showed many types of malignancies have been reported in persons with hemophilia irrespective of infection with HIV and they have high rates of malignancies compared with the general population [27]. Due to the high prevalence of oncogenic virus transmitted through blood [27, 28], HIV-infected hemophilia patients may have an increased risk of cancer. The reason for the unexpected finding of IDU was cancer risk; it is possible that heavy alcohol consumption or $\mathrm{HCV}$ infection is common among injection drug users $[29,30]$, which would affect the risk of NADCs.

In this study, half of NADC patients had advancedstage cancer. Previous reports have shown that patients with NADCs often present with more advanced-stage disease and have a poor prognosis. For example, in a study of $41 \mathrm{HIV}$ patients with hepatocellular carcinoma (HCC) and 384 controls with HCC, the HIV-infected patients had a higher risk of advanced HCC stage with multifocal and infiltrating lesions, and higher local recurrence and mortality [9]. These findings suggest that early screening and treatment of NADCs may improve the population's poorer outcome, with rapid progression and high mortality.

Our study has some limitations. Although most of the patients visited our clinic regularly every 3 months as the maximum prescription period for any drug under the Japanese health care system is limited to 3 months, cancer screening strategies and its timing were at the discretion of the treating physicians. Second, this is not a population-based but a single-center study, so selection bias is not avoidable. For instance, due to high incidence of gastrointestinal cancer in Japan, HIV expert physicians may be likely to perform abdominal CT or endoscopy than those in Western countries, leading to the relatively higher incidence of gastrointestinal cancer. Third, we did not have any information of HBV-DNA or HCV-RNA level that may affect NADC risk. Because some factors such as CD4 or HIV-RNA levels can change during long-term follow-up, time-varying covariates may have been preferable to the time-to-event models, but time-varying covariates were not available. Fourth, the accuracy of the predictive model was relatively high (c-statistic, 0.8 ), but the model could lead to an overly optimistic evaluation. Because we could collect only a small sample of NADCs $(n=61)$ in our singlecenter study, a validation study with another population or at institutions with larger numbers of subjects is needed in the future. Finally, we have no data on cancer incidence in Tokyo and could not calculate the Tokyospecific SIRs, so the expected numbers of events may be inappropriate if cancer incidence in Tokyo is different from the whole of Japan. Despite these limitations, there are several important strengths of this study. First, we could follow up $>75 \%$ of patients for $>5$ years. Second, systematically screened laboratory tests and the interviews conducted at the first visit to our hospital enabled us to collect detailed risk factors including HIV-related factors, $\mathrm{HBV}, \mathrm{HCV}$, and comorbidities for all patients. Third, the diagnosis of cancer was based on histopathological or 
cytological examination with multiple imaging modalities, which could assess cancer staging.

In conclusion, liver and colon cancer risk was elevated in Asian HIV-infected individuals, similar to in Western populations, whereas stomach cancer risk was characteristically elevated in Asian populations. Half of NADC patients were aged 40-59 years and had advanced-stage disease at diagnosis. Periodic cancer screening may be warranted for high-risk subpopulations with smoking habit, HIV infection through blood transmission or IDU, and HBV co-infection, and screening should be started over 40 years of age.

\section{Abbreviations \\ Cl: Confidence interval; COPD: Chronic obstructive pulmonary disease; HAART: Highly active anti-retroviral therapy; HBV: Hepatitis B virus; $H C V$ : Hepatitis $C$ virus; men who have sex with men; IDU: Injection drug users; IQR: Interquartile range; MSM: Men who have sex with men; NADCs: Non-AIDS-defining cancers; SIR: Standardized incidence ratio; SMR: Standardized mortality ratio; VL: Viral load}

\section{Acknowledgements}

We thank clinical research coordinators Ms. Kuniko Miki, Eiko Izawa, and Kenko Yoshida for help with data collection.

\section{Funding}

This work was supported in part by a Grant-in-Aid for AIDS research from the Ministry of Health, Labour and Welfare of Japan (H26-003), a Grant-in-Aid for AIDS research from the Japan Agency for Medical Research and Development (AMED), and Grants-in-Aid for Research from the National Center for Global Health and Medicine (29-1017 and 29-2001). The funding agencies had no role in the study design, data collection and analysis, decision to publish, or preparation of the manuscript.

\section{Availability of data and materials}

The datasets used and analyzed during the current study are available from the corresponding author on reasonable request.

\section{Authors' contributions}

NN designed the study; N.N, TN, KW, RN, KT, YK, JA, and MY collected clinical information; NN, TY, and YM performed statistical analysis; $H G, N N$, NU, and sO drafted and edited the manuscript. NN, TY, YM, RN, TN, and HG mainly edited the revised manuscript. All authors read and approved the final manuscript.

\section{Ethics approval and consent to participate}

Because this was a retrospective cohort study that was conducted without invasive procedures, and patient information was anonymized and deidentified before analysis, the requirement for patient consent was waived. This study was approved by the ethics committee of the National Center for Global Health and Medicine (Nos.1440) and was implemented in accordance with the provisions of the Declaration of Helsinki.

\section{Consent for publication}

Not applicable

\section{Competing interests}

The authors declare that they have no competing interests.

\section{Publisher's Note}

Springer Nature remains neutral with regard to jurisdictional claims in published maps and institutional affiliations.

\section{Author details}

'Departments of Gastroenterology and Hepatology, National Center for Global Health and Medicine, 1-21-1 Toyama, Shinjuku-ku, Tokyo 162-8655, Japan. ${ }^{2}$ AIDS Clinical Center, National Center for Global Health and Medicine, 1-21-1 Toyama, Shinjuku-ku, Tokyo 162-8655, Japan. ${ }^{3}$ Department of
Gastroenterology, Graduate School of Medicine, the University of Tokyo, Bunkyo-ku, Tokyo 113-8655, Japan. ${ }^{4}$ Department Director, Department of Health Promotion, National Institute of Public Health, 2-3-6 Minami, Wako, Saitama 351-0197, Japan. ${ }^{5}$ Department of Clinical Research, National Center for Global Health and Medicine, 1-21-1 Toyama, Shinjuku-ku, Tokyo 162-8655, Japan. ${ }^{6}$ Department of Gastroenterology and Hepatology, Kohnodai Hospital, National Center for Global Health and Medicine, 1-7-1, Kohnodai, Ichikawa, Chiba 272-8516, Japan.

Received: 20 September 2017 Accepted: 16 October 2018

Published online: 06 November 2018

\section{References}

1. Deeken JF, Tjen-A-Looi A, Rudek MA, Okuliar C, Young M, Little RF, Dezube BJ. The rising challenge of non-AIDS-defining cancers in HIV-infected patients. Clin Infect Dis. 2012:55(9):1228-35.

2. Wang CC, Silverberg MJ, Abrams DI. Non-AIDS-defining malignancies in the HIV-infected population. Curr Infect Dis Rep. 2014;16(6):406. https:/doi.org/ 10.1007/s11908-014-0406-0.

3. Patel $\mathrm{P}$, Hanson DL, Sullivan PS, Novak RM, Moorman AC, Tong TC, Holmberg SD, Brooks JT. Adult and Adolescent Spectrum of disease project and HIV outpatient study investigators: incidence of types of cancer among HIV-infected persons compared with the general population in the United States, 1992-2003. Ann Intern Med. 2008:148(10):728-36.

4. Chen $\mathrm{CH}$, Chung $\mathrm{CY}$, Wang LH, Lin C, Lin HL, Lin HC. Risk of cancer among HIV-infected patients from a population-based nested case-control study: implications for cancer prevention. BMC Cancer. 2015;15:133. https://doi. org/10.1186/s12885-015-1099-y.

5. Yang J, Su S, Zhao H, Wang D, Wang J, Zhang F, Zhao Y. Prevalence and mortality of cancer among HIV-infected inpatients in Beijing. China BMC Infect Dis. 2016;16(1):82. https://doi.org/10.1186/s12879-016-1416-3.

6. Silverberg MJ, Lau B, Achenbach CJ, Jing Y, Althoff KN, D'Souza G, Engels EA, Hessol NA, Brooks JT, Burchell AN, Gill MJ, Goedert JJ, Hogg R, Horberg MA, Kirk GD, Kitahata MM, Korthuis PT, Mathews WC, Mayor A, Modur SP, Napravnik S, Novak RM, Patel P, Rachlis AR, Sterling TR, Willig JH, Justice AC, Moore RD, Dubrow R. North American AIDS cohort collaboration on research and Design of the International Epidemiologic Databases to evaluate AIDS: cumulative incidence of Cancer among persons with HIV in North America: a cohort study. Ann Intern Med. 2015:163(7):507-18.

7. Clifford GM, Polesel J, Rickenbach M, Dal Maso L, Keiser O, Kofler A, Rapiti E, Levi F, Jundt G, Fisch T, Bordoni A, De Weck D, Franceschi S, Swiss HIV cohort: Cancer risk in the Swiss HIV cohort study: associations with immunodeficiency, smoking, and highly active antiretroviral therapy I Natl Cancer Inst 2005, 97(6): 425-432.

8. Chapman C, Aboulafia DM, Dezube BJ, Pantanowitz L. Human immunodeficiency virus-associated adenocarcinoma of the colon: clinicopathologic findings and outcome. Clin Colorectal Cancer. 2009;8(4):215-9.

9. Puoti M, Bruno R, Soriano V, Donato F, Gaeta GB, Quinzan GP, Precone D, Gelatti U, Asensi V, Vaccher E, HIV HCC Cooperative Italian-Spanish group. Hepatocellular carcinoma in HIV-infected patients: epidemiological features, clinical presentation and outcome. AIDS. 2004;18(17):2285-93.

10. Shiels MS, Pfeiffer RM, Gail MH, Hall HI, Li J, Chaturvedi AK, Bhatia K, Uldrick TS, Yarchoan R, Goedert JJ, Engels EA. Cancer burden in the HIV-infected population in the United States. J Natl Cancer Inst. 2011;103(9):753-62.

11. Hamada Y, Nagata N, Nishijima T, Shimbo T, Asayama N, Kishida Y, Sekine K, Tanaka S, Aoki T, Watanabe K, Akiyama J, Igari T, Mizokami M, Uemura N, Oka S. Impact of HIV infection on colorectal tumors: a prospective colonoscopic study of Asian patients. J Acquir Immune Defic Syndr. 2014;65(3):312-7.

12. Nagata N, Shimbo T, Akiyama J, Nakashima R, Nishimura S, Yada T, Watanabe K, Oka S, Uemura N. Risk factors for intestinal invasive amebiasis in Japan, 20032009. Emerg Infect Dis. 2012;18(5):717-24.

13. Fujisaki S, Yokomaku Y, Shiino T, Koibuchi T, Hattori J, Ibe S, Iwatani $Y$, Iwamoto A, Shirasaka T, Hamaguchi M, Sugiura W. Outbreak of infections by hepatitis $B$ virus genotype a and transmission of genetic drug resistance in patients coinfected with HIV-1 in Japan. J Clin Microbiol. 2011;49(3):1017-24.

14. Gatanaga H, Hayashida T. Tanuma J, Oka S. Prophylactic effect of antiretroviral therapy on hepatitis B virus infection. Clin Infect Dis. 2013;56(12):1812-9.

15. Sobin LH, Gospodarowicz MK, Wittekind C. TNM classification of malignant tumors. 2010. 
16. Matsuda A, Matsuda T, Shibata A, Katanoda K, Sobue T, Nishimoto H. Japan Cancer surveillance research group: Cancer incidence and incidence rates in Japan in 2008: a study of 25 population-based cancer registries for the monitoring of Cancer incidence in Japan (MCIJ) project. Jpn J Clin Oncol. 2014;44(4):388-96.

17. Greenson JK, Trinidad SB, Pfeil SA, Brainard JA, McBride PT, Colijn HO, Tesi RJ, Lucas JG. Gastric mucosal calcinosis. Calcified aluminum phosphate deposits secondary to aluminum-containing antacids or sucralfate therapy in organ transplant patients. Am J Surg Pathol. 1993;17(1):45-50.

18. Persson EC, Shiels MS, Dawsey SM, Bhatia K, Anderson LA, Engels EA. Retraction notice to "increased risk of stomach and esophageal malignancies in people with AIDS": Gastroenterology 2012;143:943-950.e2. Gastroenterology. 2016;150(4):1048.

19. Fock KM. Review article: the epidemiology and prevention of gastric cancer. Aliment Pharmacol Ther. 2014:40(3):250-60.

20. Naylor GM, Gotoda T, Dixon M, Shimoda T, Gatta L, Owen R, Tompkins D, Axon A. Why does Japan have a high incidence of gastric cancer? Comparison of gastritis between UK and Japanese patients. Gut. 2006;55(11):1545-52.

21. Fujiya K, Nagata N, Uchida T, Kobayakawa M, Asayama N, Akiyama J, Shimbo T, Igari T, Banerjee R, Nageshwar Reddy D, Mizokami M, Uemura N. Different gastric mucosa and CagA status of patients in India and Japan infected with helicobacter pylori. Dig Dis Sci. 2014; 59(3):631-7.

22. Sayi A, Kohler E, Hitzler I, Arnold I, Schwendener R, Rehrauer H, Muller A. The CD4+ T cell-mediated IFN-gamma response to helicobacter infection is essential for clearance and determines gastric cancer risk. J Immunol. 2009; 182(11):7085-101.

23. Barbaro G, Barbarini G. HIV infection and cancer in the era of highly active antiretroviral therapy (review). Oncol Rep. 2007;17(5):1121-6.

24. Aberg JA. The changing face of HV care: common things really are common. Ann Intern Med. 2006;145(6):463-5.

25. Saves M, Chene G, Ducimetiere P, Leport C, Le Moal G, Amouyel P, Arveile D, Ruidavets JB, Reynes J, Bingham A, Raffi F, French WHOMONICA. Project and the APROCO (ANRS EP11) study group: risk factors for coronary heart disease in patients treated for human immunodeficiency virus infection compared with the general population. Clin Infect Dis. 2003;37(2):292-8.

26. Sopori ML, Kozak W. Immunomodulatory effects of cigarette smoke J Neuroimmunol. 1998;83(1-2):148-56.

27. Dunn AL. Malignancy in patients with haemophilia: a review of the literature. Haemophilia. 2010;16(3):427-36.

28. Bodaghi S, Wood LV, Roby G, Ryder C, Steinberg SM, Zheng ZM. Could human papillomaviruses be spread through blood? J Clin Microbiol. 2005; 43(11):5428-34.

29. Galvan FH, Bing EG, Fleishman JA, London AS, Caetano R, Burnam MA, Longshore D, Morton SC, Orlando M, Shapiro M. The prevalence of alcohol consumption and heavy drinking among people with HIV in the United States: results from the HIV cost and services utilization study. J Stud Alcohol. 2002:63(2):179-86.

30. Norouzian H, Gholami M, Shakib P, Goudarzi G, Ghobadian Diali H, Rezvani A. Prevalence of HCV infections and co-infection with HBV and HIV and associated risk factors among addicts in drug treatment centers, Lorestan Province. Iran Int J High Risk Behav Addict. 2016;5(1):e25028.

\section{Ready to submit your research? Choose BMC and benefit from:}

- fast, convenient online submission

- thorough peer review by experienced researchers in your field

- rapid publication on acceptance

- support for research data, including large and complex data types

- gold Open Access which fosters wider collaboration and increased citations

- maximum visibility for your research: over $100 \mathrm{M}$ website views per year

At $\mathrm{BMC}$, research is always in progress.

Learn more biomedcentral.com/submissions 